Elsevier required licence: (c) <2018>. This manuscript version is made available under the CC-BY-NC-ND 4.0 license http://creativecommons.org/licenses/by-nc-nd/4.0/

The definitive publisher version is available online at https://doi.org/10.1016/j.compedu.2018.03.013 


\title{
The impact of an iPad-supported annotation and sharing technology on university students' learning
}

\author{
James Wakefield* \\ UTS Business School, University of Technology Sydney, Australia \\ James.Wakefield@uts.edu.au \\ Jessica K. Frawley \\ Design Lab, Faculty of Architecture, Design and Planning, University of Sydney, Australia \\ Jessica.Frawley@sydney.edu.au \\ Jonathan Tyler \\ UTS Business School, University of Technology Sydney, Australia \\ Jon.Tyler@uts.edu.au \\ Laurel E. Dyson \\ School of Software, University of Technology Sydney, Australia \\ Laurel.E.Dyson@uts.edu.au
}

*Corresponding author:

Dr James Wakefield

UTS Business School

University of Technology Sydney

PO Box 123

Broadway NSW 2007

Phone: +61 295143583

Fax: +61 295143669

Email: James.Wakefield@uts.edu.au

ORCiD: http://orcid.org/0000-0001-7269-0141 


\section{The impact of an iPad-supported annotation and sharing technology on university students' learning}

ABSTRACT: iPads, or more generally tablet computers, have received rapid and widespread uptake across higher education. Despite this, there is limited evidence of how their use affects student learning within this context. This study focuses on the use of a tablet by the instructor to support the annotation and in-class sharing of students' work to create a collaborative learning environment within a first year undergraduate subject. This paper reports the results of an empirical study looking at the effect this tablet technology has on student performance using a sample of 741 first-year accounting students. The study uses data from enrolment and attendance records, end of semester examination results and student perceptions from a survey. Results indicate that class sharing of the instructor's and students' annotation of homework through the use of a tablet is associated with an improvement in student performance on procedural or equation-based questions as well as increased student engagement. However, contrary to expectations, the introduction of in class annotations was associated with a decline in student performance on theoretical, extended response questions. The authors argue that affordances of the tablet, when used in a student-centred way, can introduce a bias towards some kinds of interactions over others. This large-scale study of inclass tablet use suggests that though the tablets may be positively associated with student engagement and satisfaction, caution must be exercised in how the use by the instructor affects the classroom environment and what students learn. These findings have particular relevance to university learning contexts with equation-centric subjects such as those in Business and STEM. 
Keywords: computer-mediated communication; cooperative/collaborative learning; improving classroom teaching; post-secondary education; teaching/learning strategies

Highlights:

- In class tablet collaboration is associated with higher performance in procedural content areas.

- In class tablet collaboration is associated with lower performance in theoretical content areas.

- Tablet use is positively associated with students' satisfaction and engagement. 


\section{Introduction}

\subsection{The rise of the iPad within education}

Since its release in 2010, the iPad and other tablet computers, have seen rapid, widespread and diverse adoption. Uniquely defined by their portability, touchscreen interface and a well-provisioned application to the marketplace (Johnson, Adams, \& Cummins, 2013; New Media Consortium, 2012), tablets are a distinct category of devices (Johnson et al., 2013) as their mobility distinguishes them from more static laptop or desktop devices and their larger screen and stylus input afford different usage to that of a smartphone devices. The innovation and potential of the iPad did not go unrecognised. In 2010, Time Magazine included the iPad within that year's 50 Best Inventions (McCracken, 2010), while in 2011, Gartner predicted Apple's domination of the tablet computing market (Gartner, 2011).

From a learning and teaching perspective, the first generation of iPad brought to life earlier conceptual prototypes such as the Xerox Dynabook (Kay, 1972) - considered to be the 'science fiction' of future learning. However, contrary to the Dynabook, the iPad itself was not explicitly designed for education. iPads and tablet computing (from this point referred to as tablets) have followed a long line of tools and technologies that have been appropriated by education from other industries and domains (see Hemmi, Bayne, \& Land, 2009; Laurillard, 2012). This tendency towards appropriation is not, in itself, problematic. New technology's ability to enable collaboration and interactivity opens up opportunities for learning and teaching. However, there is a greater need for the educational technologist and the field of educational technology to ensure the educationally sound and appropriate use of such tools (Traxler, 2016). This task is rendered especially difficult in a context where public discourse around educational technology tends towards hyperbole (Selwyn, 2016) and wider research favours positive results (Fanelli, 2010). Some early literature on tablets arguably fell into this camp, as the devices were described as "game changers" (Geist, 2011) that heralded the dawn 
of a new "post-PC" world (Murphy, 2011). However, most scholarly discussion has been more circumspect with literature, seeking to distinguish "hype" from "hope" (Nguyen, Barton, \& Nguyen, 2015) and trend and legitimate educational application (e.g. Cochrane, Narayan, \& Oldfield, 2011; Murphy, 2011).

\subsection{Adoption and use of tablets within the post-secondary education sector}

Within the post-secondary education sector, the response to tablet computers has been varied. Some institutions have made the device a central part of institution-wide curriculum reform by issuing iPads to all commencing students (Rankine-Venaruzzo \& Macnamara, 2015), while others have rolled out the technology more conservatively (Li, 2010; Raths, 2010). Adoption of tablet computers may be especially significant where instructors and educational institutions expect these technologies to enhance learning outcomes (Anderson, Schwager, \& Kerns, 2006). Both students and instructors appear to recognise the advantages associated with tablet computers, such as convenience, portability and versatility (Fisher, Lucas, \& Galstyan, 2013). As latter generations of tablets have included the option of auxiliary keyboards and styluses, the versatility of use has increased. It is hard not to be optimistic about tablets as tools for learning and teaching. In addition to their mobility, the features and near limitless combination of apps, allow for an increasingly customised and personalised user experience that naturally aligns with student centred, constructivist pedagogies.

Though such properties and affordances shape potential use, they do not dictate it. The general use of tablet computers and mobile devices in education has been seen as a way of substituting existing pedagogically conservative practices, such as pen and paper at a very basic level; this could be regarded as quite a limited or regressive use of technology given these devices' transformative potential (Herrington, Herrington, Mantei, Olney, \& Ferry, 2009; Oostveen, Muirhead, \& Goodman, 2011). Examples of such substitution can be found 
in the use of tablets in lieu of textbooks (Cross, 2010; Sloan, 2012), eReaders (Smith, Kukulska-Hulme, \& Page, 2012) and other printed materials (Bush \& Cameron, 2011). Empirical studies of tablet adoption in post-secondary education have shown conservative use of the device to substitute or augment traditional technologies or approaches (Aiyegbayo, 2014; Cavanaugh, Hargis, \& Kamali, 2013). Katzan (2015) observes that many academics have not had the time or inclination to investigate how to best integrate the use of a tablet as part of their teaching, echoing previous calls for further professional development to address this deficit (Aiyegbayo, 2014). There remains great potential to better use tablets to transform traditional learning environments by enhancing collaborations between instructors and students (Ellington, Wilson, \& Nugent, 2011; Fabian \& MacLean, 2014; Fisher et al., 2013).

\subsection{Understanding the implications of tablet adoption on student performance}

As tablet technology is adopted widely, there is a need to further examine its use and effect on student learning (Bush \& Cameron, 2011; Daccord \& Reich, 2015). Daccord and Reith (2015) identify the need to articulate a clear vision about how new technologies improve instruction and learning, as well as the need to better support students and instructors in developing the capabilities to use such technology. To date, studies within the postsecondary education context have explored student attitudes, perceptions, beliefs and learning experiences (Brand, Kinash, Mathew, \& Kordyban, 2011; Diemer, Fernandez, \& Streepey, 2012; Mayfield, O’Hara, \& O’Sullivan, 2012; Souleles, Savva, Watters, Annesley, \& Bull, 2015). Such studies on tablet use and student perceptions have focused on a range of disciplinary contexts (e.g. Diemer et al., 2012), including art and design (Souleles et al., 2015), digital media (Brand et al., 2011) and mathematics-based subjects (Fisher et al., 2013; Fister \& McCarthy, 2008). Though student perceptions and attitudes are well understood, the impact of tablet use in the classroom on student performance is poorly understood. One study shows that the tablet had no impact on student learning at all (Perez, Gonzalez, Pitcher, \& 
Golding, 2011). A recent systematic review (Nguyen et al., 2015) shows existing studies of tablet use within the post-secondary education are typically exploratory, small in scale, or 'one-off' studies that are unclear as to the impact the device is having on learning. As faculty educators and teachers adopt tablets at a large-scale (see Rankine-Venaruzzo, Macnamara \& Griffin, 2014), there is a need for equally large-scale studies to explore what these devices can do for learning. In summary, evidence from both the literature and from educational practice suggests that there is a critical need for large-scale studies of educational uses of tablets that focus on student outcomes as well as other frequently explored variables such as student satisfaction and engagement.

\section{Purpose and research question}

This paper addresses gaps within the research literature on the effects of tablet use in the classroom based on a study of their use in an introductory accounting subject at a large Australian metropolitan university. Previous findings on the same cohort found a positive association between tablet use and student engagement and motivation (Author citation, 2015). Building on this earlier study, this paper focuses on the role that the use of tablets has on student performance, informed by an ordinary least squares (OLS) regression of exam and student record data from 741 students. At the time of writing, this study is the largest of its kind and the only one to focus on the impact of tablet use in the classroom on different concepts in learning. As such, rather than measure performance solely through the aggregate final exam mark, this study measures the relationship between different types of disciplinary learning as indicated through types of in-class learning activities and exam questions. This study addresses a significant gap in the literature on tablet use within post-secondary education and has particular relevance for those in similar business or STEM disciplines where equation-based content makes live annotation especially valuable. This investigation contributes a more informed approach, consistent with calls from the educational technology 
literature (see Daccord \& Reich, 2015; Drouin, Vantanian, \& Birk, 2014; Nguyen et al., 2015).

\subsection{Research question}

The following research question was developed from gaps in the literature and the specifics of tablet-enabled annotation and sharing technology application which is the focus of this paper. The research question informs the research design and data collection of this study.

- How does the introduction of tablet-enabled annotation and sharing technology affect student performance in the final exam?

\section{Educational technology and context}

A tablet-based teaching solution was introduced into tutorials of up to 40 students in a large compulsory first-year accounting subject. The subject is compulsory for many students (including business and non-business degrees) and accordingly students' preconceived views of the subject are mixed. Some students initially perceive the subject as boring and irrelevant, leading to low motivation and preference for surface learning approaches (Biggs, 1999; McGuigan \& Weil, 2011). The subject has a high failure rate (around 25\%) relative to other introductory subjects offered by the business school. Within this setting, tutorials are used for students to share written homework and go through worked examples of their choosing with the tutor and their peers. Within the subject, content and learning activities can be broadly categorised into two types:

Procedural knowledge: Procedural knowledge accounts for approximately $85 \%$ of the disciplinary content of the subject. Learning and assessment activities typically focus on numerical and equation-based questions involving the consolidation and interpretation of accounting information. The exam question focuses on procedural 
content knowledge, which is also reflective of the homework exercises students complete (provided in Appendix A).

2) Theoretical knowledge: Theoretical knowledge accounts for approximately $15 \%$ of the disciplinary content of the subject. Learning and assessment activities typically focus on case study questions, which students have to respond to through long answer text that integrate quantitative and qualitative understandings of the subject. The exam question focuses on theoretical knowledge, which is also reflective of the homework exercises students complete (provided in Appendix B).

Prior to introducing the tablet, students would say which questions from the homework they would like to focus on, with student requests reflecting the 85:15 ratio of procedural to theoretical knowledge. Though students could nominate what homework questions they wanted to focus on, contextual observational inquiry (see Author citation, 2015) found tutorials to be largely didactic and teacher-centric in nature.

To address this issue, a tablet was used to capture, display and annotate students' written work live within a classroom tutorial environment. Similar to tutorial practice prior to the tablet introduction, the tutor asks students which exercises they would like to discuss. The process, illustrated in Figure 1, typically begins with students volunteering to share their written homework with the instructor and class. The instructor or student then uses the tablet to photograph and annotate the handwritten homework, with the tablet transmitting an image of this to the data projector.

\section{[INSERT FIGURE 1 HERE]}

The tablet was chosen as its size and mobility afforded mixed student-teacher use while supporting the handwritten annotations that occur within equation-based subjects. Though the specific context of this paper is undergraduate accounting, the authors argue that 
the findings can be applied to other STEM or equation-based disciplines where there may be multiple correct ways of solving a single problem.

\section{Theoretical and pedagogical approach}

Technology and its usage are never neutral or value free. In the case of educational technologies, what we use and how we use it manifest our fundamental beliefs, values and assumptions about how we learn. Rendering these theories visible and explicit is important for understanding the specific design intentions behind any given educational technology and its use. The theories that guided this implementation are detailed below.

\subsection{Learner-centred pedagogies}

The use of a tablet to make students' works the centre of the learning deliberately counters the prior focus on the textbook and instructor examples. Approaches that shift the focus to the student (learner) build upon constructivist philosophies of education (e.g. Bruner, 1986; Dewey, 1966; Vygotsky, 1986) that see both the learner and learning as active, interpretative and interactional in nature. Student-centred approaches have long been recognised as important within post-secondary education (Biggs \& Tang, 2003; Prosser \& Trigwell, 1999; Ramsden, 1992). The use of digital technologies has long been recognised as one way educators can move away from transmission modes of learning that focus on instructors presenting and explaining solutions (Prosser \& Trigwell, 1999). In the 1990s, there was a focus on the design of student-centred learning environments (SCLE) and the use of computer mediated communication to give students space to learn and think rather than only receive transmitted information (Land \& Hannafin, 2000).

\subsection{Collaborative digital annotation}

Annotation has long been used by humans to engage with a range of materials, from writing in the margins of bibles and medieval manuscripts, through to Fermat's last theorem 
that was handwritten in the margins of Diophantus' Arithmetica. Annotation is a routine part of a reader's active engagement with a text or resource. In post-secondary education, research on annotations in textbooks has found that students find the annotations and markings made by other students useful (Marshall, 1997). Digital technologies allow annotation to be collaborative in nature. Earlier studies of digital annotation in education focused on those that used a cursor or typed keyboard entry (Hwang, Wang, \& Sharples, 2007; Nokelainen, Miettinen, Kurhila, Floréen, \& Tirri, 2005). However, tablet computers have allowed for wider uptake of the screen-based input of touch or stylus, which supports handwritten annotations. Within education, handwritten digital annotation has been widely used in the delivery of materials such as that of the Khan Academy (https://www.khanacademy.org/) and also by instructors in live lecture delivery (Lee $\&$ Lim, 2013). The ability to digitally annotate any document and then share this document wirelessly has been found to be useful in teaching mathematics (Fister \& McCarthy, 2008). The tablet, and its ubiquitous uptake, makes this kind of learning more widely accessible than those previously available through PDA and tablet tools. While, non-electronic styluses have always been part of the tablet market, whether in devices such as the Palm Pilot or in the uptake of non-electronic stylus accessories, the design and development of digital pens by Apple, Samsung and Microsoft for their specific range of tablets further cements and legitimises the use of the tablet for handwritten and hand drawn input. In addition to the educational benefits of the annotation as a mark on a screen, the tablet also supports use that is more collaborative. In a comparative study of tablets and laptops for teaching business calculus, tablets were found to allow students to "transition back and forth from private to public work spaces" (Fisher et al., 2013, p. 165). In summary, for equation-based subjects such as accounting and others in business and finance, the tablet supports multiple users and viewers within and across different spaces. 
In the practical application that is the focus for this study, the tablet connects studentgenerated worked examples completed outside the classroom to annotations and discussion between the tutor and multiple student users in the classroom. In adopting collaborative digital annotation with a student-centred focus, the approach has the potential to increase student participation by encouraging them to complete homework problems prior to the tutorial to share in class to resolve any questions and discuss challenges experienced.

\section{Method}

The analysis of tablet annotation and sharing technology on student learning was carried out in three stages. First, our prior exploratory study (Author citation, 2015) examined student attitudes and perceptions of the use of a tablet to photograph, display and annotate students' work, while identifying any issues before proceeding with tablet use in subsequent teaching semesters. The exploratory study indicated that students found tutorials engaging and more interactive when using a tablet. Students also felt comfortable sharing their work using the tablet, liked the feedback and liked comparing their understanding relative to fellow students. Second, reported in this paper, we compare the differences in student perceptions of the tutorial learning environment, pre and post-introduction of the tablet. These first two stages are important in framing the third and constitute a principal part of this study aiming to better understand how the tablet affects student performance. We present the data collection approach by using student results and records, as well as the OLS regression model to test for performance implications.

\subsection{Student perceptions}

To examine whether the differences in student perceptions of tutorial pre and postintroduction of the tablet are significant, we analyse data collected from a centrally administered online survey by the university to gauge students' perception of their learning experience. The survey was administered to students in the semesters prior to and post the 
introduction of the tablet, allowing for a comparison of differences in students' satisfaction, specifically relating to the instructor that used of the tablet. Survey data was collated from the pre and post tablet enabled tutorials led by the same instructor. This is important to control for other factors related to multiple instructor experience and teaching styles that may affect student satisfaction. The Wilcoxon signed-rank test was used to compare the difference in students' satisfaction over the two periods (pre and post tablet tablet). This test is appropriate given it is a non-parametric test comparing two sample related means, consistent with the ordinal and non-normal distribution of the survey data. Students were asked to rate their agreement with six statements using a five point Likert scale ranging from strongly disagree (Likert scale point 1) to strongly agree (Likert scale point 5) relating to tutor preparedness, helpfulness, encouragement, effectiveness and overall satisfaction. Over the pre and post tablet use period, 236 students completed the centrally administered survey or $31.85 \%$ of students enrolled over the period that completed all assessments. ${ }^{1}$

\subsection{Performance implications}

To examine the performance implications of the tablet, a series of OLS regressions are run. These OLS regression models examine the implications of tablet use (independent dummy variable, $\beta_{1}$ ) on final exam performance. The models also include a series of control variables, which are described in the independent variable section below. The following equation is representative of the OLS regression models run:

$$
\begin{aligned}
& \text { Exam_performance }_{i}=\beta_{0}+\beta_{1} \text { Tablet_Use_Dummy } y_{i}+\beta_{2} \text { Accounting_Major_Dummy } y_{i}+ \\
& \beta_{3} \text { Age }_{i}+\beta_{4} \text { Campus_Dummy } y_{i}+\beta_{5} \text { Gender_Dummy }{ }_{i}+\beta_{6} G P A_{i}+\beta_{7} \text { Year_of_Study } y_{i}+\varepsilon_{i}
\end{aligned}
$$

The sample of students used to run the regressions consists of 741 students, of whom 197 were enrolled in tutorials where the tablet was used, whilst the remaining 544 were

\footnotetext{
${ }^{1}$ Given the survey was administered online and voluntary, $31.85 \%$ appears to be an acceptable response rate. Students are reminded by email and by the learning management system multiple times to complete the survey to mitigate non-response bias.
} 
enrolled in tutorials prior to the introduction of the tablet. These 741 students (pre and post) were enrolled in the one instructor's tutorial, consistent with the survey data analysed in this paper. The students' subject level performance (final exam) was used as the basis of the performance measure and university records were used for the independent variables.

\subsubsection{Dependent variables}

Two OLS regressions are run using the results of two different exam questions as the dependent variable, thereby enabling us to examine two different performance areas and observe whether they are affected differently by tablet use. The first relates to student performance in a procedural question focusing on financial statement analysis and associated interpretation (provided in Appendix A). The second relates to performance in a theoretically focused question requiring students to interpret and make decisions concerning accounting method appropriateness and suggest alternatives and remedies to the situation (provided in Appendix B). These two areas were chosen due to the clear contrast in the type of understanding required in introductory accounting - from basic procedural knowledge (financial statement analysis) to deeper comprehension of accounting method appropriateness and alternative choices (accounting theory). Both questions (Appendix A and B) are worth equal marks in the final exam. Examining the implications on these two distinct performance areas is important to understand how technology might be applied in different areas of learning, which vary considerably within and outside the domain of accounting courses. The nature of the exam questions throughout the study period (pre and post tablet) remained consistent in terms of content and difficulty levels, facilitating a reliable comparison of performance. 


\subsubsection{Independent variables}

Tablet use

This is the independent dummy variable of interest in this study. A positive and significant coefficient for this variable indicates that the tablet is related to higher student performance. This variable is assigned a value of 1 for students enrolled in the tutorial using the tablet and 0 otherwise.

\section{Accounting major}

Students majoring in accounting may exhibit higher levels of motivation and associated engagement, accordingly realising higher exam performance. This dummy variable is assigned a value of 1 for students majoring in accounting, and 0 otherwise.

Age

Student maturity is argued to be a predictor of better performance (Edmonds \& Edmonds, 2008). Accordingly, we calculate a continuous measure of student age at the time each student studied the introductory accounting subject.

\section{Campus}

The introductory accounting subject is a compulsory subject in both the business degree and business-related degrees across the two campuses where the tablet technology was used. While the business degree is taught at both campuses, the business-related degree was taught exclusively at the small campus where the tablet was used. This has resulted in negative attitudes and perceptions of the subject at the small campus, which may negatively affect performance (Jackling, De Lange, Phillips, \& Sewell, 2012; McGuigan \& Weil, 2011). Accordingly a dummy variable is assigned a value of 1 for the small campus, and 0 for main campus. 


\section{Gender}

Gender has been shown to be associated with different learning approaches and associated performance in some cases (Schleifer \& Dull, 2009). The variable is assigned a value of 1 for males and 0 for female students.

\section{Grade point average (GPA)}

Past performance is argued to be predictive of future performance (Wooden, 1998). Grade point average, a continuous variable, refers to the average marks students have received across their studies, excluding the introductory accounting subject.

\section{Year of study}

Students in later years of study appear to have higher metacognition levels and therefore higher performance (Sperling, Howard, Staley, \& DuBois, 2004). Students might study the introductory accounting subject at any stage of their degree and accordingly this variable provides a continuous measure of year of study at the time students studied the subject.

\section{Findings}

\subsection{Student perceptions}

Students' general satisfaction with the instructor was determined from an analysis of the six question student survey as shown in Table 1, which was conducted pre and post introduction of the tablet. Based on average Likert scale responses, as well as the comparison between pre and post-introduction of the tablet, there is an increase in student satisfaction across all survey question responses, with the exception of item five; 'The tutor helped me to see the connections between the tutorials and the rest of the subject' (based on the Wilcoxon signed-rank test), summarised in Table 1. These improvements in survey results are associated with the introduction of the tablet. Specifically, it appears students perceived the 
tablet to be an important resource to facilitate the learning process (survey item one), generating enhanced student understanding and participation (survey item two and three respectively). Further, the tablet improved understanding relative to other students and improved their comfort in tutorials to actively participate (survey item four).

\section{[INSERT TABLE 1 HERE]}

Consistent with survey question ratings, the instructor observed substantially higher rates of homework completion and student discussion in tutorials when using the tablet. Supporting these views is students' higher uptake of the option to allocate part of their total assessment mark to the tutorial. Students could choose to allocate $10 \%$ of their assessment based on homework completion and class participation (class mark) and reduce the weighting of the mid-semester exam from $40 \%$ to $30 \%$ of their total assessment. Students made this choice after they had experienced three tutorials and were assessed on the remaining nine tutorials. Prior to the use of the tablet, less than half of students selected the class mark option; however, after the tablet was introduced, more than $75 \%$ chose this option. The selection of the class mark option is reflective of higher rates of homework completion after the tablet was introduced.

Consistent with student feedback, instructor observations suggest that higher rates of homework completion and class participation may be explained by a number of factors, including students' ability to convey their questions more clearly through the tablet and the instructor being able to provide more tailored and relevant feedback in discussions with students. In addition, students' motivation to complete homework may also be driven by seeing their peers' work and feeling the need to similarly complete the required work prior to class. Students were asked to voluntarily share their homework responses through the tablet so that higher rates of homework completion were not driven by a fear of being required to 
share responses. Students appeared to be comfortable engaging in class discussions and using the tablet, as the instructor did not judge students on the correctness of their responses, consistent with the purpose of tutorials to address student questions and gaps in their accounting knowledge.

\subsection{Performance implications}

\subsubsection{OLS regression main results}

The descriptive statistics of the regression model variables are provided in Table 2 below and indicate sufficient variation for the purpose of the regression analysis.

\section{[INSERT TABLE 2 HERE]}

The results of the OLS regressions demonstrate that all models are significant at the one percent level, as indicated by the F-statistic. The main regression results, presented in Table 3, indicate a substantial proportion of student performance is explained with $\mathrm{R}$ squares of $36.9 \%$ and $25.1 \%$ in the financial statement analysis and accounting theory regression models respectively. The control variables are also significant in many cases, indicating they capture variation in students' subject performance beyond that explained by the tablet use (the dummy variable of interest).

The results for the effect of tablet use on student performance in the procedural financial statement analysis question are provided in Panel A of Table 3 . They indicate the tablet has a positive and significant effect (coefficient $0.187 ; p$-value 0.000 ) on performance in procedural equation-based questions. This supports our initial conjecture that tablet use would improve student learning. This aligns with the first study (Author citation, 2015) that found student homework completion and participation in class had improved after the introduction of the tablet. 
The results for the effect of tablet use on student performance in the theoretically complex question are provided in Panel B of Table 3. Student performance contrasts significantly with results from the procedural equation-based question. In particular, these results indicate that the tablet is negatively and significantly associated with lower student performance in the final exam (coefficient $0.290 ; p$-value 0.000 ). This challenges our initial expectation; one would have expected higher performance to be associated with the use of the tablet; the results indicate that this is not the case.

\section{[INSERT TABLE 3 HERE]}

There are a number of reasons that might explain the negative performance effects on the theoretical question. First, while there is a $85: 15$ ratio of procedural (practical) to theoretical (extended response) exercises, the tutorial material covered is structured around students' own questions and challenges, meaning the instructor focuses on these areas. The tablet appears to fit well with discussions concerning procedural introductory accounting homework exercises. These exercises generally have 'correct' answers and 'correct' formats; while there is variation allowed, these variations are usually limited, easily demonstrated and explained. Quickly annotating and focusing on the key issues students face is a distinct advantage of using the tablet in this context. Accordingly, students focus much of their questions on such homework exercises, rather than on more theoretical extended response exercises, which are more time consuming, not as easy to annotate in real-time and challenging to facilitate a shared discussion. This is especially the case when a single word can change the meaning but often a variety of synonyms are acceptable and are encouraged as individual expression (Handal, Campbell, Cavanagh, \& Petocz, 2016). As a result, rather than aligning students' motivations and efforts to thoroughly complete all the homework exercises, the tablet intervention instead appears to have motivated students to focus on the procedural based exercises. In short, the authors suggest that while the tablet enables fast, 
structured and handwritten equation-based feedback, it also introduces a preferential bias for these types of questions over others that are less aligned. This finding also needs to be considered in the context of a compulsory introductory subject where students' underlying motivation and dedication may be low, with surface based approaches to learning being more common (Biggs, 1999; Palm \& Bisman, 2010). Thus, students may find the tablet very useful in helping them to understand procedural introductory accounting content, which they perceive as essential to pass the subject, due to the $85: 15$ procedural to theoretical content ratio, rather than aspiring to learn more deeply and achieve higher results. Further, this may reinforce the effort students perceive they need to devote to theoretical content, reducing the deep understanding they acquire concerning these topic areas. This is consistent with concerns raised in the literature that suggest mobile devices encourage shallow learning as students look for quick resolutions, rather than spending time to analyse the underlying logic (Handal et al., 2016).

The implications of the technology on failure rates should also be noted. While the impact of the tablet technology on students' performance is small but significant, the marks for the examination questions we examine cluster around the $50 \%$ pass mark. The mean and median marks for the financial statement analysis question are 9.031 and 9.000 and for the accounting theory question, they are 8.803 and 9.000 respectively. Both examination questions are marked out of a maximum of 20. These effects on performance and associated mean and median marks highlight the important implications tablet technology can have students' likelihood of passing the subject. The results indicate that students with borderline marks seeking to merely pass the subject, consistent with the motivations of many students studying compulsory introductory accounting subjects (McGuigan \& Weil, 2011), will benefit significantly in the more procedural questions, which introductory accounting is largely comprised, reducing failure rates. However, a subject where the content and 
associated examinations are much more theoretically based, the technology is likely to be less

effective and may increase failure rates.

\subsubsection{OLS regression sensitivity testing}

The diversity of students enrolled in the introductory accounting subject indicates sensitivity testing is warranted to examine the robustness of the results presented in Table 3 . The authors conducted sensitivity analysis by splitting the sample on the basis of median mid-semester exam mark, final exam mark and grade point average (GPA), as these marks are expected to be reflective of students' dedication and commitment levels and, accordingly, may be associated with different outcomes of the tablet, including students' disposition to surface based learning approaches (Biggs, 1999; Palm \& Bisman, 2010). We also split the sample based on whether the students selected the class mark option (Option A indicates nonselection and Option B indicates selection). Given these variables may be associated with different learning approaches, the association between tablet use and performance effects may be different, suggesting the presence of moderation effects. The results are reported in Tables 4 and 5 below. These results are consistent with the main results, indicating the performance effect findings are robust and these variables are not associated with moderation effects. While the tablet use dummy variable coefficients vary, the differences are not substantial and are all statistically significant at the one percent level.

\section{[INSERT TABLE 4 \& 5 HERE]}

Further, we examine if accounting choice of major and campus enrolment (small or main campus) variables have moderation effects on tablet effectiveness. It is possible these variables are related to different student perceptions of the introductory accounting subject and motivation levels leading to different study patterns, as explained in the regression model variable definitions earlier in the paper. Further, interpretation differences arising from 
variation in cultural background related to campus enrolment and major choice may also be present (Chand, Cummings, \& Patel, 2012; Jackling et al., 2012). The regression results based on the sample excluding students not majoring in accounting (the number of students majoring in accounting is insufficient to run the regression) and the individual campuses are consistent with those reported earlier, again indicating the results are robust and not subject to moderating effects.

\section{$7 \quad$ Discussion and conclusions}

Our study highlights the importance of investigating the implications of the diverse array of tablet-based technologies being deployed in post-secondary education on student learning and performance. Tablets are widely used in post-secondary education, with significant investment being made by the educational sector, often without substantial empirical evidence on the impact this has on the many diverse aspects that constitute student learning. Contrary to the early hype associated with tablets (e.g. Geist, 2011; Murphy, 2011), the results of this study do not offer a straightforward or universally marketable conclusion. In response to the original research question, 'how does the introduction of tablet-enabled annotation and sharing technology affect student performance in the final exam?' the answer is mixed as the tablet-enabled annotation and sharing technology led to higher performance in one kind of question at the expense of other types of learning. This was found to be the case even when other variables were controlled for in conditions that were pedagogically informed by best practice and validated with data demonstrating improved student satisfaction and engagement.

This study found the tablet to be effective in motivating students to complete their homework in preparation for the tutorial. This is important for the style of problem based learning adopted in this subject. Within class, the tablet was found to support more active and 
engaging tutorial environments, where the norm included students volunteering their own work for display, annotation and discussion (Author citation, 2015). This more studentcentred approach contrasts with the passive learning environment in the absence of the tablet, which this tool was introduced to alleviate (Author citation, 2015). As indicated by the student survey results, the use of tablets in tutorials led to a significant improvement in general satisfaction, with students perceiving the tablet to be beneficial to enhancing tutorial engagement, interaction, comfort when participating in class discussion and evaluating their understanding relative to other students. This continues to support existing research into iPads and student satisfaction and engagement.

However, while student attitudes and perceptions of the tablet improved, this study reveals a demonstrable break between students' perceptions of their learning, as judged by student satisfaction and the actual outcomes of that learning as evidenced within the final exam. In particular, student performance appears to improve in more procedural-based areas of accounting, while it appears to decrease in more theoretically-based areas. Though exams may be considered to be crude samples of the entirety of a student's learning, these results, nevertheless, indicate that the tablet has had a highly statistically significant effect on what students learn. In short, the findings suggest that the tablet introduces a preferential bias towards students and tutors focusing on procedural equation-based questions, instead of those theoretical questions that are less suited to the shared class-based annotation approach. This finding must be interpreted within the context of a mandatory introductory first year subject. In this context, student motivation, self-efficacy and self-determination towards mastery may be low and lead to more surface-based learning approaches (Biggs \& Tang, 2003). This may especially be the case for first year students, who may be less adept at self-regulation and erroneously perceive the subject content ratio of procedural to theoretical material, $85: 15$ respectively, as an indication of the relative importance of these different types of materials 
(see Zimmerman, 1998). In this context, centring the class learning on what students want may have led students to focus on those questions that they are comfortable with and/or perceive as essential to passing the subject. Further, we argue that the affordances (see Norman 1988) of the iPad technology and the stylus toward writing procedural equationbased annotation lend themselves more readily to the tablet interaction. Sensitivity tests indicate the results are very robust to variation in the sample according to students' dedication and commitment levels.

Combined, these findings offer a significant contribution to the body of knowledge. From a theoretical perspective, these findings draw attention to the limits of our ability to control and determine how an educational technology will impact on learning and teaching. Though the unique relational properties of a technology to its user can afford certain kinds of use (Norman 1988) with tools being able to mediate human experiences and practice (Verbeek, 2015), neither educators nor educational technologists can know precisely how a given tool will be appropriated by the instructor and students within the realities of the classroom. While we can adopt new technologies with the best of theoretically and empirically supported learner-centred pedagogies, tools and approaches will continue to be appropriated in ways that technologists, teachers and students may not anticipate. This findings should not dissuade educators and students from adopting new tools; rather it emphasises the need to continue to evaluate and research these tools through studies and methods that recognise the myriad of ways that any given educational technology may have on student learning. While tablet technology uptake may be diverse within post-secondary education, as Nguyen et al. (2015) demonstrate, research into this area is less diverse, with few studies focusing on performance, and even fewer using large scale samples and methods. This study addresses this gap within the literature. In addition, where existing research into iPad impact on student performance does exist (e.g. Perez et al., 2011), our work is able to 
contribute a more nuanced measure of performance. Rather than seeing performance as a single or aggregate measure, this research distinguishes between the different kinds of learning demonstrable within the final exam and, through this sensitive measure, is better positioned to understand student performance in this context.

For educators, administrators and practitioners, awareness of these issues allows for more critical examination of how tablet technology may be implemented, especially within equation-centred subjects. Teachers may wish to use the tablet to highlight the different acceptable approaches students have taken to answering the same question but, having facilitated initial participation using the tablet, may decide to put the tablet aside and discuss the extended responses. Care needs to be exercised in not allowing the tablet to consume an inordinate amount of time, especially when questions have a format that is difficult to verbally describe but easy to project. These findings are especially relevant for those seeking to improve mathematical problem-based learning in disciplines such as STEM and business.

There are limitations of this study and associated considerations for future research. First, our analysis of performance implications centres on students studying a compulsory introductory accounting subject. While we conduct sensitivity testing, based on student dedication and commitment levels, there is the possibility of other factors moderating the implications of the tablet technology on students' performance including those previously mentioned: motivation, self-efficacy, self-determination and self-regulation. Students in other equation based disciplines in Business, STEM and other subjects may have greater levels of motivation and self-regulation, possibly related to intrinsic interest in the subject, resulting in being less influenced by the nature of technology in the classroom affecting their homework completion, engagement, learning and performance. However, this is something that can only be known through future research. Future work may wish to replicate this study in other disciplines and contexts. Second, there is also the potential to breakdown the performance 
implications of the tablet technology into narrower content and topic areas. We chose to examine and contrast the implications for two areas, procedural and theoretical knowledge. While these two areas are very important in the context of introductory accounting course material, the consideration of different topic areas in more detail, consistent with the nature of the subject material, may be appropriate for other disciplines.

In summary, this large-scale empirical study addresses gaps within the literature while highlighting the variation in learning outcomes from the use of tablet-based technologies. The results of this study reinforce both the need for critical, evidence-based analysis of learning outcomes from the use of new technologies to ensure it is meeting the intended learning outcomes and the need to recognise that students and teachers will appropriate new technologies in unexpected ways. Like other literature in the field, this research cautions against the blanket adoption of technology without a more in-depth analysis of the full educational implications. The results from this study contribute evidence which may inform how we might adopt and implement tablets in post-secondary education, especially for equation focused subjects in STEM and business disciplines where the visual depiction is paramount in some parts but distracting in others. 


\section{Acknowledgements}

We would like to thank: the Computers \& Education co-editor, Professor Miguel Nussbaum, the two anonymous reviewers, Paul de Lange, Tom Downen, Jere Francis, Paul Wells, the anonymous conference reviewers and participants at the 2016 AAA annual meeting, AFAANZ conference, EAA conference, mLearn conference and the UTS First Year Experience Forum for their valuable comments and suggestions. 


\section{References}

Aiyegbayo, O. (2014). How and why academics do and do not use iPads for academic teaching? British Journal of Educational Technology, 46(6), 1324-1332. doi: 10.1111/bjet.12202

Anderson, J. E., Schwager, P. H., \& Kerns, R. L. (2006). The drivers for acceptance of tablet PCs by faculty in a college of business. Journal of Information Systems Education, 17(4), 429-440.

Biggs, J. (1999). What the student does: teaching for enhanced learning. Higher education research \& development, 18(1), 57-75.

Biggs, J., \& Tang, C. (2003). Teaching for Quality Learning at University (New edition ed.): Society for Research into Higher Education and Open University Press.

Brand, J., Kinash, S., Mathew, T., \& Kordyban, R. (2011). iWant does not equal $i$ Will: correlates of mobile learning with iPads, e-textbooks, BlackBoard Mobile Learn and a blended learning experience. Paper presented at the Changing Demands, Changing Directions. Proceedings ASCILITE Conference, Hobart, Australia.

Bruner, J. (1986). Actual minds, possible worlds. Cambridge, MA: Harvard University Press.

Bush, M. H., \& Cameron, A. H. (2011). Digital course materials: A case study of the Apple iPad in the academic environment. Pepperdine University.

Cavanaugh, C., Hargis, J., \& Kamali, T. (2013). Substitution to augmentation: faculty adoption of iPad mobile learning in higher education. Interactive Technology and Smart Education, 10(4), 279-284. doi: http://dx.doi.org/10.1108/ITSE-01-2013-0001

Chand, P., Cummings, L., \& Patel, C. (2012). The Effect of Accounting Education and National Culture on Accounting Judgments: A Comparative Study of Anglo-Celtic and Chinese Culture. European Accounting Review, 21(1), 153-182.

Cochrane, T., Narayan, V., \& Oldfield, J. (2011). iPadagogy: Appropriating the iPad wtihin Pedagogical Contexts. Paper presented at the 10th World Conference on Mobile and Contextual Learning (mLearn), Beijing, China.

Cross, K. (2010). iPad replaces uni textbooks at University of Adelaide science faculty. The Advertiser. Retrieved 03 May, 2017, from http://www.adelaidenow.com.au/technology/ipad-replaces-uni-textbooks-atuniversity-of-adelaide-science-faculty/newsstory/5d199c5ea0587eb097391b090334bcbb

Daccord, T., \& Reich, J. (2015). How to transform teaching with tablets. Educational Leadership, 72(8), 18-23.

Dewey, J. (1966). Democracy and Education: an introduction to the philosophy of education. New York: Free Press.

Diemer, T. T., Fernandez, E., \& Streepey, J. W. (2012). Student perceptions of classroom engagement and learning using iPads. Journal of Teaching and Learning with Technology, 1(2), 13-25.

Drouin, M., Vantanian, L. R., \& Birk, S. (2014). A community of practice model for introducing mobile tablets to university faculty. Innovative Higher Education, 39(3), 231-245.

Edmonds, C. T., \& Edmonds, T. P. (2008). An empirical investigation of the effects of SRS technology on introductory managerial accounting students. Issues in Accounting Education, 23(3), 421-434.

Ellington, A. J., Wilson, J. H., \& Nugent, J. S. (2011). Use of table PCs to enhance instruction and promote group collaboraton in a course to prepare future mathematics specialists. Mathematics and Computer Education, 45(2), 92-105. 
Fabian, K., \& MacLean, D. (2014). Keep taking the tablets? Assessing the use of tablet devices in learning and teaching activities in the further education sector. Research in Learning Technology, 22.

Fanelli, D. (2010). "Positive" results increase down the hierarchy of the sciences. PLoS ONE, 5(4), 1-10. doi: https://doi.org/10.1371/journal.pone.0010068

Fisher, B., Lucas, T., \& Galstyan, A. (2013). The role of iPads in constructing collaborative learning spaces. Technology, Knowledge and Learning, 18(3), 165-178.

Fister, K. R., \& McCarthy, M. L. (2008). Mathematics instruction and the tablet PC. International Journal of Mathematical Education in Science and Technology, 39(3), 285-292.

Gartner. (2011). Gartner says Apple iOS to dominate the media tablet market through 2015, owning more than half of it for the next three years. Retrieved 3 April, 2017, from http://www.gartner.com/newsroom/id/1626414

Geist, E. A. (2011). The game changer: using iPads in college teacher education classes. College Student Journal, 45(4), 758-768.

Handal, B., Campbell, C., Cavanagh, M., \& Petocz, P. (2016). Characterising the perceived value of mathematics educational apps in preservice teachers. Mathematics Education Research Journal, 28(1), 199-221.

Hemmi, A., Bayne, S., \& Land, R. (2009). The appropriation and repurposing of social technologies in higher education. Journal of Computer Assisted Learning, 25, 19-30.

Herrington, J., Herrington, A., Mantei, J., Olney, I. W., \& Ferry, B. (2009). New technologies, new pedagogies: Mobile learning in higher education.

Hwang, W.-Y., Wang, C.-Y., \& Sharples, M. (2007). A study of multimedia annotation of Web-based materials. Computers \& Education, 48, 680-699.

Jackling, B., De Lange, P., Phillips, J., \& Sewell, J. (2012). Attitudes towards accounting: Differences between Australian and international students. Accounting Research Journal, 25(2), 113-130.

Johnson, L., Adams, S., \& Cummins, M. (2013). The NMC Horizon Report: 2013 higher education edition. Austin, TX: The New Media Consortium.

Katzan, H. (2015). Principles of tablet computing for educators. Contemporary Issues in Education Research, 8(1), 7.

Kay, A. C. (1972). The personal computer for children of all ages. Paper presented at the ACM National Conference, Boston, MA.

Land, S., \& Hannafin, M. (2000). Student-centred learning environments. In D. Jonassen \& S. Land (Eds.), Theoretical foundations of learning environments (pp. 1-23). Mahwah, NJ: Lawrence Erlbaum Associates.

Laurillard, D. (2012). Teaching as a design science: Building pedagogical patterns for learning and technology. London: Routledge.

Lee, H. W., \& Lim, K. Y. (2013). Does digital handwriting of instructors using the iPad enhance student learning? Asia-Pacific Education Researcher, 22(3), 241-245.

Li, S. (2010). Williston State College gives iPads to professors. Chronicle of Higher Education, 57(2), 23.

Marshall, C. (1997). Annotation: from paper books to the digital library. Retrieved 17 May, 2017, from http://www.csdl.tamu.edu/ marshall/d197.pdf

Mayfield, C. H., O’Hara, P. T., \& O'Sullivan, P. S. (2012). Perceptions of a mobile technology on learning strategies in the anatomy laboratory. Anatomical Sciences Education, 6(2), 81-89.

McCracken, H. (2010). The 50 Best Inventions of 2010: iPad. Time Magazine. Retrieved 3 May, 2017, from 
http://content.time.com/time/specials/packages/article/0,28804,2029497_2030652,00. $\underline{\mathrm{html}}$

McGuigan, N., \& Weil, S. (2011). Addressing a 'preconceptual threshold': A transformation in student preconceptions of introductory accounting. Critical Perspectives on Communication, Cultural and Policy Studies, 30(2), 15-33.

Murphy, G. D. (2011). Post-PC devices: A summary of early iPad technology adoption in tertiary environments. e-Journal of Business Education \& Scholarship of Teaching, 5(1), 18-32.

New Media Consortium. (2012). Tablet Computing: Time-toAdoption Horizon: One year or less NMC Horizon Report: 2012 K-12 Edition (pp. 15-18).

Nguyen, L., Barton, S. M., \& Nguyen, L. T. (2015). iPads in higher education-Hype and hope. British Journal of Educational Technology, 46(1), 190-203.

Nokelainen, P., Miettinen, M., Kurhila, J., Floréen, P., \& Tirri, H. (2005). A shared document-based annotation tool to support learner-centred collaborative learning. British Journal of Educational Technology, 36(5), 757-770.

Norman, D. (1988). The design of everyday things. New York: Basic Books.

Oostveen, R., Muirhead, W., \& Goodman, W. (2011). Tablet PCs and reconceptualizing learning with technology: A case study in higher education. Interactive Technology and Smart Education, 8(2), 78-93.

Palm, C., \& Bisman, J. (2010). Benchmarking introductory accounting curricula: Experience from Australia. Accounting Education, 19(1-2), 179-201.

Perez, O. A., Gonzalez, V., Pitcher, M. T., \& Golding, P. (2011). Work in progress: Analysis of mobile technology impact on STEM based courses; specifically introduction to engineering in the era of the iPad. Paper presented at the 118th ASEE Annual Conference and Exposition, Vancouver, BC, Canada.

Prosser, M., \& Trigwell, K. (1999). Understanding learning and teaching: The experience in higher education: McGraw-Hill International).

Ramsden, P. (1992). Learning to Teach in Higher Education. London: Routledge.

Rankine-Venaruzzo, L., \& Macnamara, D. (2015). iPads as Educational Tools. In Y. A. Zhang (Ed.), Handbook of Mobile Teaching and LEarning (pp. 691-703). Berlin Heidelberg: Springer-Verlag.

Rankine-Venaruzzo, L., Macnamara, D., \& Griffin, T. I. p.-. (2014). Changing the face of learning @ UWS. In B. Hegarty, J. McDonald, \& S.-K. Loke (Eds.), Rhetoric and Reality: Critical perspectives on educational technology. Proceedings ASCILITE Dunedin 2014 (pp. 58-68): Australasian Society for Computers in Learning in Tertiary Education.

Raths, D. (2010). Mobile learning on campus: Balancing on the cutting edge. Campus Technology, 24(3), 19.

Schleifer, L. L., \& Dull, R. B. (2009). Metacognition and performance in the accounting classroom. Issues in Accounting Education, 24(3), 339-367.

Selwyn, N. (2016). Minding our language: why education and technology is full of bullshit... and what might be done about it. Learning, Media and Technology, 41(3), 437-443. doi: http://dx.doi.org/10.1080/17439884.2015.1012523

Sloan, R. H. (2012). Using an eTextbook and iPad: results of a pilot program. Journal of Educational Technology Systems, 41(1), 87-104.

Smith, M., Kukulska-Hulme, A., \& Page, A. (2012). Educational use cases from a shared exploration of e-books and iPads. . In G. Tiong-Thye (Ed.), E-Books and E-Readers for E-Learning. (pp. 25-53). Wellington, New Zealand: Victoria Business School, Victoria University of Wellington. 
Souleles, N., Savva, S., Watters, H., Annesley, A., \& Bull, B. (2015). A phenomenographic investigation on the use of iPads among undergraduate art and design students. British Journal of Educational Technology, 46(1), 2015.

Sperling, R. A., Howard, B. C., Staley, R., \& DuBois, N. (2004). Metacognition and selfregulated learning constructs. Educational Research and Evaluation, 10(2), 117-139.

Traxler, J. (2016). Students and mobile devices. ALT-J, Research in Learning Technology, $18(2), 149-160$.

Verbeek, P. P. (2015). Cover story: Beyond interaction: a short introduction to mediation theory. Interactions, 22(3), 24-31.

Vygotsky, L. (1986). Thought and Language (A. Kozulin, Trans.). Cambridge, MA: The MIT Press.

Wooden, T. C. (1998). Factors influencing student learning in introductory accounting classes: A comparison of traditional and nontraditional students. Issues in Accounting Education, 13(2), 357-374.

Zimmerman, B. J. (1998). Academic studing and the development of personal skill: A selfregulatory perspective. Educational Psychologist, 33(2-3), 73-86. 


\section{Appendix A: Procedural question ${ }^{2}$}

Financial Statement Analysis

(Total marks: 20 marks)

The following data is presented for Ramjets Ltd for the Financial Years Ended September 30.

Ramjets Ltd

Comparative Statements of Financial Position

As at the $30 / 09 / 2014$

As at the $30 / 09 / 2013$

Current Assets

Cash

$\$ 440$

$\$ 520$

3,500

2,470

Accounts Receivable (net)

3,400

3,800

Supplies

90

Prepaid Insurance

70

190

Total Current Assets

7,500

6,990

Non-current Assets

Land

10,500

6,000

Buildings

12,800

9,840

Less Accumulated Depreciation

$(6,500)$

$\underline{(4,330)}$

Total Non-current Assets

16,800

11,510

Total Assets

$\underline{24,300}$

$\underline{18,500}$

Current Liabilities

Accounts Payable

Notes Payable

1,500

1,300

870

780

860

680

Total Current Liabilities

3,230

2,760

Non-current Liabilities

Mortgage

6,000

5,000

3,570

2,000

1,000

1,000

Long term Loan

Total Non-current Liabilities

10,570

8,000

Total Liabilities

$\underline{13,800}$

10,760

Shareholders' Equity

Contributed Capital

7,000

7,000

Retained Profits

$\underline{4,500}$

740

Total Shareholders' Equity

10,500

$\underline{7,740}$

Total Liabilities \& Shareholders’ Equity

$\underline{24,300}$

$\underline{18,500}$

Question continues next page ${ }^{2}$ Areas for student responses have been reduced for the purposes of this paper in the interests of conserving
length. 


\section{Ramjets Ltd}

Comparative Statements of Comprehensive Income

For the years ending 30/09/2014 and 30/09/2013

Net Sale (all on credit)

Cost of Goods Sold

Gross Profit

Less Expenses:

Advertising \& Selling

Salaries \& Wages

Suppliers Expense

Interest Expenses

Total Expenses

Profit before Income Tax

Income Tax

Comprehensive Income after Tax
2014

197,850

$\underline{(128,596)}$

69,254

2,500

17,350

3,654

18,600

42,104

27,150

$(8,545)$

18,605
2013

207,588

$(132,500)$

75,088

3,300

21,015

12,106

12,495

48,916

26,172

$(7,852)$

18,320

\section{PART A: Ratio Analysis}

(6 marks)

From the data in Question 2 above, calculate the following three 'ratios' (one mark each) for Ramjets Ltd for the year ending 30/09/2014 or as at 30/09/2014 (not as at 30/09/2013). Comment on a limitation of the ratio (one mark each) when analysing a business.

1. Accounts Receivable Turnover Ratio

Your Answer (rounded to 1 decimal place):

Comment on a limitation of the accounts receivable turnover ratio

2. Inventory Turnover Ratio

Your Answer (rounded to 1 decimal place):

Comment on a limitation of the inventory turnover ratio

\section{Current Ratio}

Your Answer (rounded to 1 decimal place):

Comment on a limitation of the current ratio 
REQUIRED: Using the financial statements above, complete the following questions in relation to vertical (within one year) and horizontal (across two years) analysis. In calculation questions please remember to indicate if it is an INCREASE or (DECREASE) and round your findings to ONE decimal place [e.g. $-32.446 \%$ is $-32.5 \%$ or minus $32.5 \%$ or $(32.5 \%)$ ].

1. Explain why a user of financial statements may undertake vertical analysis ( 2 marks)

\section{Gross Profit (2 marks)}

Vertical Analysis 2014 :

Horizontal Analysis

\section{Total Expense (2 marks)}

Vertical Analysis 2014 :

Horizontal Analysis :

4. Comprehensive Income after Tax (2 marks)

Vertical Analysis 2014 :

Horizontal Analysis

5. Following on from your analysis above, comment briefly on your findings about the profitability of the business. (Confine your comments to the analysis of Gross Profits, Total Expenses and Comprehensive Income after Tax) (2 marks)

\section{Land (2 marks)}

Vertical Analysis 2014 :

Horizontal Analysis

7. Total Current Liabilities (2 marks)

Vertical Analysis 2014 :

Horizontal Analysis 


\section{Appendix B: Theoretical question}

Earnings Management

(Total marks: 20 marks)

\section{Case:}

SwissTech Ltd recently opened a new flagship store in the CBD to sell the finest quality watches it sources from a company based Switzerland. The managing director of SwissTech Ltd invites you to become an investor in the business as it aims to reduce debt levels. As part of the invitation to invest, you have been provided with the following statement of comprehensive income (all figures in thousands) relating to the first year of operations:

SwissTech Ltd

Statement of Comprehensive Income

Year ending 30 June 2014

Sales revenue

COGS

Gross profit

Operating expenses:

Salaries expense $\quad 1,000$

Depreciation of flagship store expense $\quad 150$

Bad debts expense $\quad 10$

Other expenses $\quad 5$

Net profit $\quad 1,025$

You have done some research on this business and found a number of potential concerns:

- There is concern about the impact of the upcoming "Apple Watch" on the demand for more traditional watches, like those sold by SwissTech. The Apple Watch is expected to be substantially cheaper and offer connectivity and features not currently available in the watches SwissTech sells.

- SwissTech Ltd invested heavily in the new flagship store. The store was very busy during the first 3 months of operation; however, demand has since decreased substantially. It appears many buyers are keen to buy the new Apple Watch. Sales staff indicated that customers are still willing to purchase SwissTech watches, but only with substantial discounts. This situation is not expected to improve with the upcoming release of the Apple Watch, as well as similar products from competitors. You investigated the current research and development activities of the supplier in Switzerland and have been informed that there are no new products in development. The supplier maintains they produce the finest watches and research and development investment is not necessary.

- Many of the watches are sold to customers on credit, given the high prices. Some customers are foreign tourists, who have returned home and failed to make the monthly instalments as they fall due. Management are in the process of following these customers up to seek repayment; however, this is a challenging process since sales staff were not thorough in recording customer details and performing credit checks.

Question continues next page 
Your inquiries with the financial controller at SwissTech Ltd indicate the following accounting methods are being used:

- Straight line depreciation of long-term assets (in particular the flagship store) over 15 years with a $50 \%$ residual value

- Direct write off of bad debts

\section{Required:}

1. Discuss the appropriateness of accounting methods with references to the guidance provided by the Generally Accepted Accounting Principles (GAAP) and accounting standards. ( 8 marks)

2. To what extent do you think the management of SwissTech Ltd is attempting to engage in earnings management? Identify and explain any accounting methods you think would provide a more informative view of this company's financial performance. (6 marks)

3. Justify any additional information that you require to make an informed decision about investment in the business which could include financial and/or management accounting information. (6 marks)

Answer requirements 1, 2 and 3 in the space provided on the following pages (6 pages provided) 


\section{Figure}

Figure 1. Tablet image sharing and annotation within class

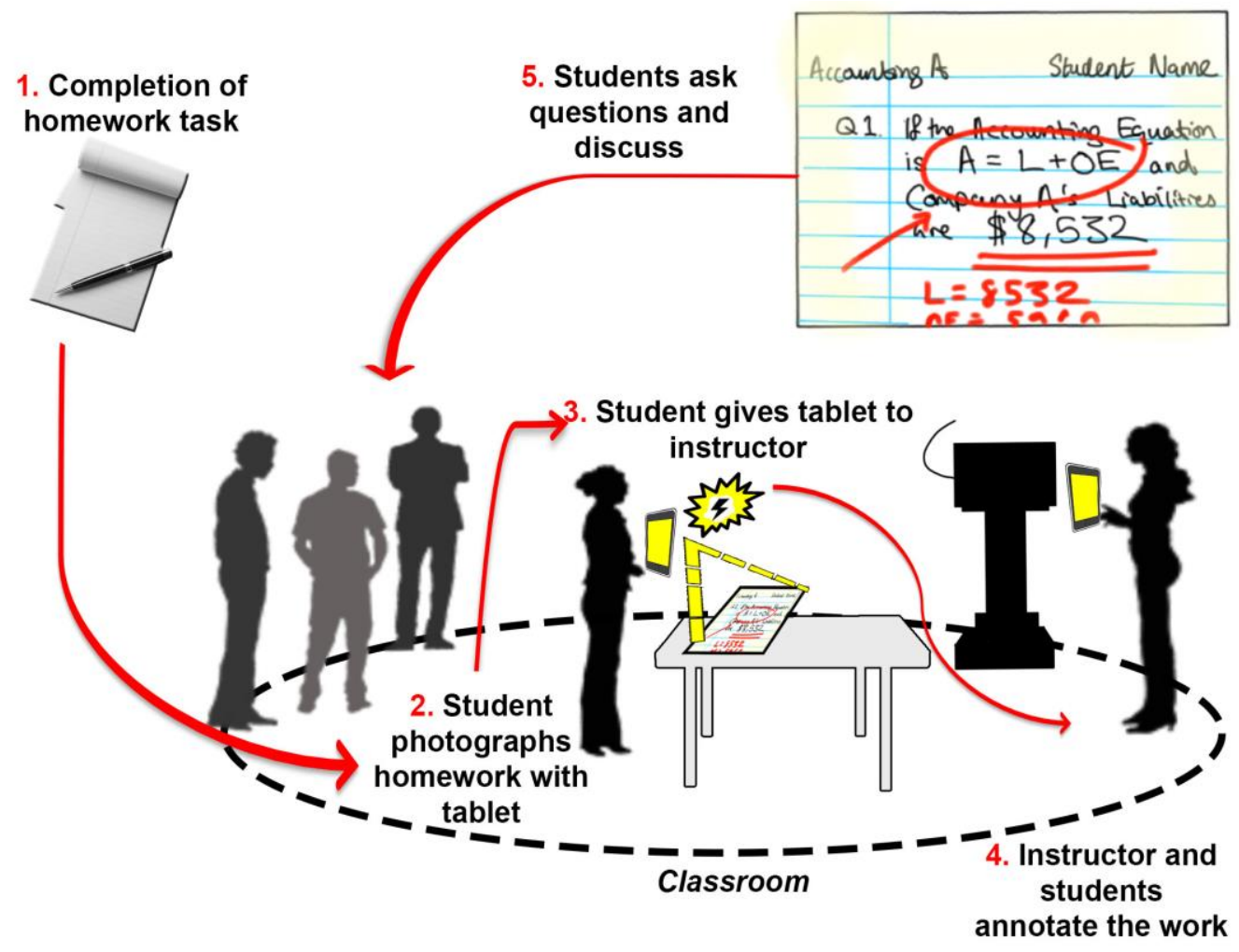




\section{Tables}

Table 1

Survey of students' general satisfaction with tutor (instructor).

\begin{tabular}{|c|c|c|c|c|c|}
\hline \multirow[b]{2}{*}{ Item } & \multirow[b]{2}{*}{ Question } & \multirow{2}{*}{\multicolumn{2}{|c|}{$\begin{array}{l}\text { Prior to tablet } \quad \text { Tablet introduced } \\
\text { (Average on } 1-5 \text { Likert scale) }\end{array}$}} & \multicolumn{2}{|c|}{ Wilcoxon signed-rank test } \\
\hline & & & & Z-statistic & $p$-value \\
\hline 1 & The tutor came to class well prepared to help me learn. & 4.205 & 4.641 & 2.252 & 0.024 \\
\hline 2 & The tutor helped me to understand the material I was learning. & 3.928 & 4.359 & 2.033 & 0.042 \\
\hline 3 & The tutor encouraged me to participate in class. & 3.651 & 4.344 & 3.698 & 0.000 \\
\hline 4 & The tutor created a comfortable environment for students to ask questions. & 3.873 & 4.266 & 2.773 & 0.006 \\
\hline 5 & $\begin{array}{l}\text { The tutor helped me to see the connections between the tutorials and the rest } \\
\text { of the subject. }\end{array}$ & 3.916 & 4.234 & 1.460 & 0.144 \\
\hline 6 & Overall, I am satisfied with the teaching of this tutor. & 3.898 & 4.344 & 2.423 & 0.015 \\
\hline
\end{tabular}


Table 2

Descriptive statistics and frequencies for complete sample* $(n=741)$.

Panel A: Descriptive statistics - continuous variables

\begin{tabular}{lrrrrr}
\hline & Min. & Max. & Mean & Median & Std. Dev. \\
\hline Financial statement analysis performance & 0.000 & 20.000 & 9.031 & 9.000 & 5.218 \\
Accounting theory performance & 0.000 & 20.000 & 8.803 & 9.000 & 5.113 \\
Age & 18.167 & 38.167 & 20.347 & 19.583 & 2.528 \\
GPA & 2.000 & 89.333 & 64.509 & 65.489 & 10.882 \\
Year of study & 0.000 & 4.500 & 0.538 & 0.500 & 0.806 \\
\hline
\end{tabular}

Panel B: Frequencies - dummy variables

Binary codes

\begin{tabular}{lcc}
\hline & 0 & 1 \\
\hline Tablet use & 544 & 197 \\
Accounting major & 616 & 125 \\
Campus & 514 & 227 \\
Gender & 406 & 335
\end{tabular}

*The statistics reported in this table are based on the non-normalised variables. Where appropriate the variables are normalised, consistent with the assumptions of OLS regression. 


\section{Table 3}

Tablet computing performance effects.

Panel A: Financial statement analysis performance effects $(n=741)$

\begin{tabular}{lcc}
\hline Independent variables & Coefficient & $t$-statistic \\
\hline Tablet use dummy & $0.187^{* * * *}$ & 5.677 \\
Accounting major dummy & $0.216^{* * *}$ & 7.005 \\
Age & 0.009 & 0.288 \\
Campus & $-0.309^{* * *}$ & -8.592 \\
Gender dummy & 0.040 & 1.357 \\
GPA & $0.432^{* * *}$ & 14.147 \\
Year of study & $0.063^{*}$ & 1.791 \\
& & \\
Adjusted $\mathrm{R}^{2}$ & 0.369 & \\
F-stat $(p$-value) & $62.873^{* * *}$ & \\
& $(0.000)$ & \\
\hline
\end{tabular}

Panel B: Accounting theory performance effects $(n=741)$

\begin{tabular}{lcr}
\hline Independent variables & Coefficient & $t$-statistic \\
\hline Tablet use dummy & $-0.290^{* * *}$ & -8.085 \\
Accounting major dummy & $0.096^{* * *}$ & 2.846 \\
Age & $-0.151 * * *$ & -4.330 \\
Campus & 0.013 & 0.328 \\
Gender dummy & -0.044 & -1.357 \\
GPA & $0.351 * * *$ & 10.533 \\
Year of study & 0.043 & 1.109 \\
& & \\
Adjusted $\mathrm{R}^{2}$ & 0.251 & \\
F-stat ( $p$-value) & $36.493 * * *$ \\
& $(0.000)$ & \\
\hline$* * *$ Significant at the 0.01 level; **Significant at the 0.05 level; $*$ Significant at the 0.10 level (2-tailed)
\end{tabular}


Table 4

Tablet computer performance effects on financial statement performance: Sensitivity testing.

\begin{tabular}{|c|c|c|c|c|c|c|c|c|c|}
\hline & $\begin{array}{c}\text { Tablet use } \\
\text { dummy }\end{array}$ & $\begin{array}{l}\text { Accounting } \\
\text { major dummy }\end{array}$ & Age & Campus & $\begin{array}{l}\text { Gender } \\
\text { dummy }\end{array}$ & GPA & $\begin{array}{c}\text { Year of } \\
\text { study }\end{array}$ & & \\
\hline & & & & ficient (t-stat) & & & & F-stat & $\begin{array}{l}\text { Adj. R } \\
\text { square }\end{array}$ \\
\hline $\begin{array}{l}\text { All students } \\
(n=741)\end{array}$ & $\begin{array}{l}0.187 * * * \\
(5.677)\end{array}$ & $\begin{array}{l}0.216^{* * *} \\
(7.005)\end{array}$ & $\begin{array}{c}0.009 \\
(0.288)\end{array}$ & $\begin{array}{l}-0.309 * * * \\
(8.592)\end{array}$ & $\begin{array}{c}0.040 \\
(1.357)\end{array}$ & $\begin{array}{l}0.432 * * * \\
(14.147)\end{array}$ & $\begin{array}{r}0.063^{*} \\
(1.791)\end{array}$ & $62.873 * * *$ & 0.369 \\
\hline $\begin{array}{l}\text { Low mid-semester } \\
(n=316)\end{array}$ & $\begin{array}{l}0.265^{* * *} \\
(4.956)\end{array}$ & $\begin{array}{c}0.100^{*} \\
(4.956)\end{array}$ & $\begin{array}{c}0.009 \\
(0.159)\end{array}$ & $\begin{array}{l}-0.324 * * * \\
(-5.505)\end{array}$ & $\begin{array}{c}0.033 \\
(0.641)\end{array}$ & $\begin{array}{l}0.342 * * * \\
(6.663)\end{array}$ & $\begin{array}{c}0.025 \\
(0.434)\end{array}$ & $14.450 * * *$ & 0.230 \\
\hline $\begin{array}{l}\text { High mid-semester } \\
(n=331)\end{array}$ & $\begin{array}{l}0.233^{* * *} \\
(4.406)\end{array}$ & $\begin{array}{l}0.270 * * * \\
(5.509)\end{array}$ & $\begin{array}{c}0.068 \\
(1.334)\end{array}$ & $\begin{array}{l}-0.285 * * * \\
(-5.071)\end{array}$ & $\begin{array}{c}0.077 \\
(1.631)\end{array}$ & $\begin{array}{l}0.351 * * * \\
(7.293)\end{array}$ & $\begin{array}{c}0.089 \\
(1.561)\end{array}$ & $20.811 * * *$ & 0.296 \\
\hline $\begin{array}{l}\text { Low final exam } \\
(n=368)\end{array}$ & $\begin{array}{l}0.275^{* * *} \\
(4.919)\end{array}$ & $\begin{array}{l}0.150 * * * \\
(3.022)\end{array}$ & $\begin{array}{l}-0.015 \\
(-0.281)\end{array}$ & $\begin{array}{l}-0.259 * * * \\
(-4.322)\end{array}$ & $\begin{array}{l}-0.037 \\
(-0.733)\end{array}$ & $\begin{array}{l}0.201 * * * \\
(3.968)\end{array}$ & $\begin{array}{l}-0.032 \\
(-0.561)\end{array}$ & $8.976^{* * *}$ & 0.132 \\
\hline $\begin{array}{l}\text { High final exam } \\
(n=369)\end{array}$ & $\begin{array}{l}0.298 * * * \\
(5.918)\end{array}$ & $\begin{array}{l}0.217 * * * \\
(4.434)\end{array}$ & $\begin{array}{c}0.078 \\
(1.504)\end{array}$ & $\begin{array}{l}-0.228 * * * \\
(-4.310)\end{array}$ & $\begin{array}{c}0.053 \\
(1.114)\end{array}$ & $\begin{array}{l}0.275^{* * * *} \\
(5.628)\end{array}$ & $\begin{array}{l}0.117 * * \\
(2.048)\end{array}$ & $14.895 * * *$ & 0.209 \\
\hline $\begin{array}{l}\text { Low GPA } \\
(n=348)\end{array}$ & $\begin{array}{l}0.198 * * * \\
(3.448)\end{array}$ & $\begin{array}{l}0.260 * * * \\
(5.181)\end{array}$ & $\begin{array}{l}-0.029 \\
(-0.551)\end{array}$ & $\begin{array}{l}-0.344 * * * \\
(-5.632)\end{array}$ & $\begin{array}{c}0.064 \\
(1.296)\end{array}$ & $\begin{array}{l}0.225^{* * *} \\
(4.586)\end{array}$ & $\begin{array}{l}0.150 * * * \\
(2.628)\end{array}$ & $12.954 * * *$ & 0.194 \\
\hline $\begin{array}{l}\text { High GPA } \\
(n=393)\end{array}$ & $\begin{array}{l}0.208 * * * \\
(4.364)\end{array}$ & $\begin{array}{l}0.223 * * * \\
(4.865)\end{array}$ & $\begin{array}{c}0.054 \\
(1.133)\end{array}$ & $\begin{array}{l}-0.324 * * * \\
(-6.389)\end{array}$ & $\begin{array}{c}0.029 \\
(0.657)\end{array}$ & $\begin{array}{l}0.267 * * * \\
(5.949)\end{array}$ & $\begin{array}{c}0.001 \\
(0.014)\end{array}$ & $23.034 * * *$ & 0.282 \\
\hline $\begin{array}{l}\text { Option A } \\
(n=261)\end{array}$ & $\begin{array}{l}0.220 * * * \\
(4.302)\end{array}$ & $\begin{array}{l}0.198 * * * \\
(3.927)\end{array}$ & $\begin{array}{c}0.046 \\
(0.862)\end{array}$ & $\begin{array}{l}-0.351 * * * \\
(6.496)\end{array}$ & $\begin{array}{l}0.110 * * \\
(2.266)\end{array}$ & $\begin{array}{l}0.455^{* * *} \\
(9.270)\end{array}$ & $\begin{array}{c}0.106^{*} \\
(1.851)\end{array}$ & $25.498 * * *$ & 0.397 \\
\hline $\begin{array}{l}\text { Option B } \\
(n=480)\end{array}$ & $\begin{array}{l}0.131 * * * \\
(2.978)\end{array}$ & $\begin{array}{l}0.231 * * * \\
(5.857)\end{array}$ & $\begin{array}{c}-0.022 \\
(-0.549)\end{array}$ & $\begin{array}{l}-0.282 * * * \\
(-5.801)\end{array}$ & $\begin{array}{c}0.029 \\
(0.753)\end{array}$ & $\begin{array}{l}0.400 * * * \\
(10.086)\end{array}$ & $\begin{array}{c}0.050 \\
(1.097)\end{array}$ & $36.384 * * *$ & 0.341 \\
\hline
\end{tabular}


Table 5

Tablet computer performance effects on accounting theory performance: Sensitivity testing.

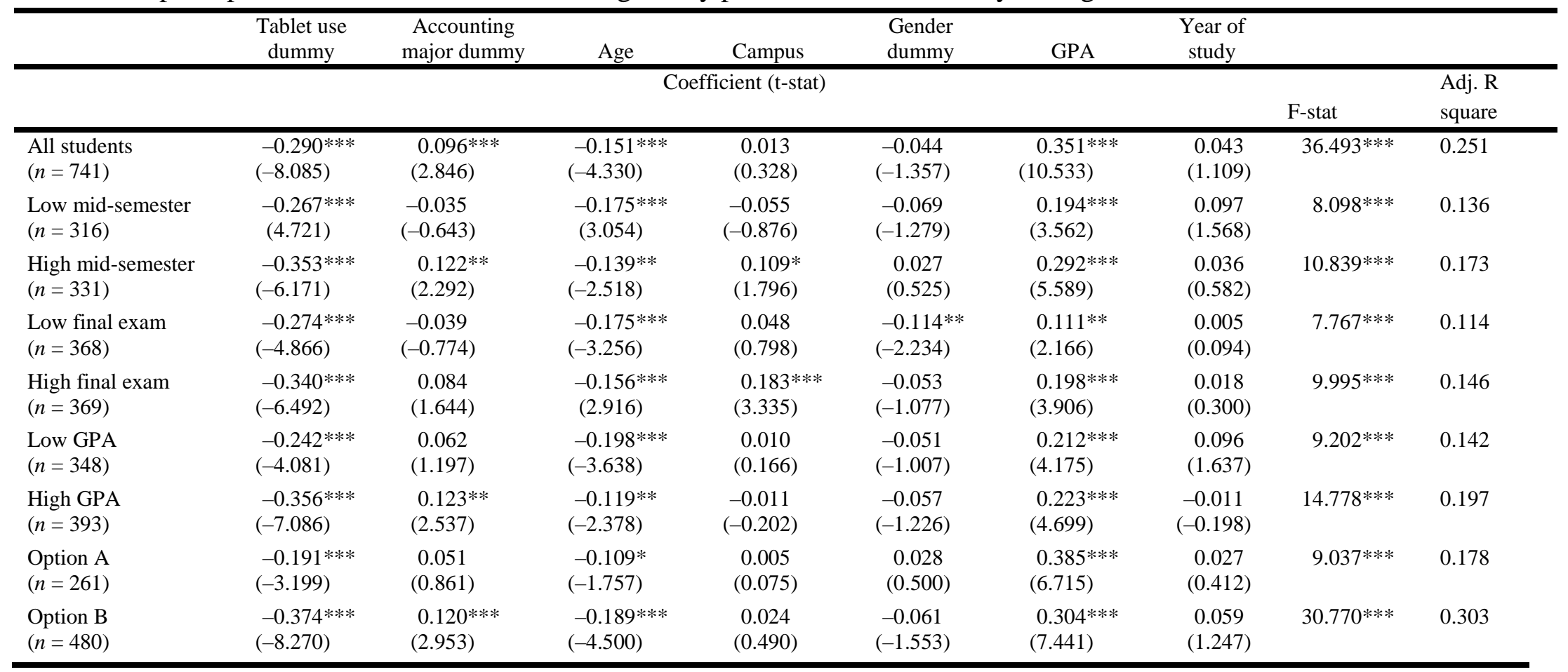

***Significant at the 0.01 level; **Significant at the 0.05 level; *Significant at the 0.10 level (2-tailed) 